\title{
Valve-sparing root replacement: Still so much to learn
}

\author{
Leonard N. Girardi, MD, and Mario F. Gaudino, MD
}

\author{
From the Department of Cardiothoracic Surgery, Weill Cornell Medicine, New York, NY. \\ Disclosures: Authors have nothing to disclose with regard to commercial support. \\ Received for publication April 20, 2017; accepted for publication May 26, 2017; available ahead of print June 20, \\ 2017. \\ Address for reprints: Leonard N. Girardi, MD, 525 E 68th St, M-404, New York, NY 10065 (E-mail: lngirard@ \\ med.cornell.edu). \\ J Thorac Cardiovasc Surg 2017;154:798-9 \\ $0022-5223 / \$ 36.00$ \\ Copyright $(C 2017$ by The American Association for Thoracic Surgery \\ http://dx.doi.org/10.1016/j.jtcvs.2017.05.085
}

More than 2 decades after its introduction, valve-sparing aortic root replacement (VSRR) has become a standard procedure in the surgical armamentarium of cardiothoracic surgeons across the globe. In expert hands, the operation can be performed with very low operative risk and excellent longterm durability. ${ }^{1}$ Because these outcomes rival those of root replacement with a composite valve-graft, ${ }^{2}$ VSRR can be considered the procedure of choice for younger patients, those with connective tissue disorders, and patients who need or wish to avoid lifelong anticoagulation therapy.

Oechtering and colleagues ${ }^{3}$ present the 4-dimensional (4D) flow magnetic resonance imaging (MRI) images from 3 patients who underwent the David 1 VSRR using a straight tube graft. In 2 patients, the authors report malrotated systolic vortices behind the coronary leaflets. The orientation of these vortices appears markedly different from normal volunteers and may lead to increased systolic contact of the valve leaflets with graft material, higher leaflet stress, and an increased incidence of valve failure.

4-D flow MRI has the enormous potential to capture in vivo fluid dynamics in the aortic root by focusing on patient-specific patterns of blood velocity. Nonetheless, a more quantitative evaluation and a larger sample size will be necessary to fully exploit 4-D flow MRI data in patients undergoing VSRR, especially given the myriad surgical techniques and grafts espoused for use in VSRR surgery. Although several variables are currently computed from 4-D flow MRI data; for example, wall shear stress, relative pressure field, and turbulent kinetic energy, further studies will be needed to validate the computational process and to translate these results into clinically relevant information. The rapid development of MRI technology, as well as the ongoing optimization of 4-D flow MRI acquisition sequences, will allow a more refined in vivo quantification of fluid dynamics and may ultimately tell us which VSRR technique is best.

At the heart of the matter is the importance of the recreation of the sinuses of Valsalva. Experimental evidence suggests that in normal human beings the Valsalva sinuses play a vital role in aortic valve function, energy propagation, and coronary blood flow. ${ }^{4}$ Surgical techniques and dedicated

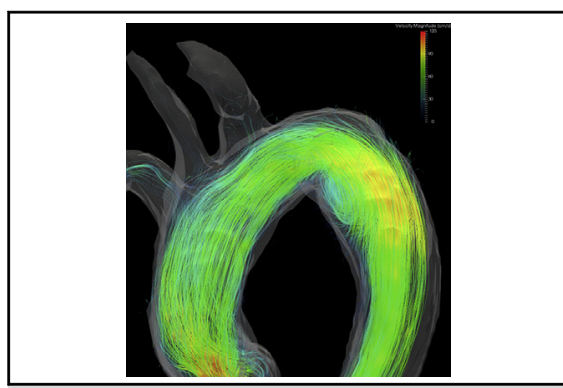

Magnetic resonance imaging-generated fluid dynamics in the ascending aorta and arch.

\section{Central Message}

Debate continues regarding the most physiologic method of valve-sparing aortic root reconstruction. Magnetic resonance imaginggenerated computational fluid dynamics provide data that may prove 1 technique superior.

See Article page 794.

grafts aimed at recreating the sinuses have been proposed and may offer advantages over straight tube grafts. ${ }^{5}$ However, to date only very limited comparisons between patients undergoing the different techniques are available. The short- and long-term effects of sinus re-creation are largely unknown.

This article by Oechtering and colleagues ${ }^{3}$ is an excellent example of modern translational research. Cardiothoracic surgeons are using a vast array of new technology such as 4-D flow MRI and computational fluid dynamics to more clearly differentiate surgical techniques beyond usual outcomes reporting. Instead of just applying advanced statistics that fewer and fewer of us understand, we are collaborating with colleagues in other disciplines to provide comprehensible theories on the best aortic root physiology. This type of in-depth investigation of the physics of the aortic root is just the beginning. As larger cohorts of patients undergoing VSRR with a variety of techniques are examined, ultimately it is patients who stand to benefit the most.

\section{References}

1. David TE, Feindel CM, Webb GD, Colman JM, Armstrong S, Maganti M. Longterm results of aortic valve-sparing operations for aortic root aneurysm. J Thorac Cardiovasc Surg. 2006;132:347-54.

2. Gaudino M, Lau C, Munjal M, Avgerinos D, Girardi LN. Contemporary outcomes of surgery for aortic root aneurysms: A propensity-matched comparison of valvesparing and composite valve graft replacement. J Thorac Cardiovasc Surg. 2015; 150:1120-9.

3. Oechtering TH, Frydrychowicz A, Sievers HH. Malrotated sinus vortices in straight graft valve-sparing aortic root treatment: a matter of concern? J Thorac Cardiovasc Surg. 2017; 154:794-7. 
4. Pisani G, Scaffa R, Ieropoli O, Dell'Amico EM, Maselli D, Morbiducci U, et al. Role of the sinuses of Valsalva on the opening of the aortic valve. J Thorac Cardiovasc Surg. 2013;145:999-1003.
5. De Paulis R, Chirichilli I, Scaffa R, Weltert L, Maselli D, Salica A, et al. Longterm results of the valve reimplantation technique using a graft with sinuses. $J$ Thorac Cardiovasc Surg. 2016;151:112-9. 